\title{
The role of attention and study time in explicit and implicit memory for unfamiliar visual stimuli
}

\author{
DONNA GANOR-STERN \\ National Institute for Testing and Evaluation, Jerusalem, Israel \\ JOHN G. SEAMON \\ Wesleyan University, Middletown, Connecticut \\ and \\ MARISA CARRASCO \\ New York University, New York, New York
}

\begin{abstract}
The effects of limited attentional resources and study time on explicit and implicit memory were studied using Schacter and Cooper's possible and impossible objects in their recognition and object decision paradigm. In one experiment, when attention at study was limited by a flanking digits procedure, object recognition was diminished but object decision priming for possible objects was unaffected; in another experiment, limiting attention plus reducing stimulus study time impaired object recognition and eliminated object priming. Recognition memory and perceptual priming for previously unfamiliar visual stimuli were both influenced by attention, although to different degrees. The intervening variable of study time determined the degree to which priming was affected by attentional resources. These results support a limited capacity attentional model for both recognition and perceptual priming of unfamiliar visual stimuli, and they highlight the need for assessing the interaction of attentional resources and study time in explicit and implicit memory tasks.
\end{abstract}

Explicit memory refers to the conscious, intentional recollection of past experience, whereas implicit memory refers to the unintentional, nonconscious retrieval of previously acquired information (Graf \& Schacter, 1985). Explicit memory is typically measured by direct tests of memory such as free recall, cued recall, and recognition, whereas implicit memory is measured by indirect memory tests that do not ask subjects to recollect specific prior experiences. In tests such as word identification, wordstem completion, and affective preference, implicit memory is inferred when subjects show a facilitation or change in performance that is attributable to information acquired during study. This change is often referred to as priming. Over the past decade, considerable research has shown that explicit and implicit memory can be dissociated by a variety of experimental variables. Examples of those variables include stimulus encoding instructions, study-test changes in the stimuli, and length of the re-

This research was part of the Wesleyan University Master's thesis of D.G.-S. conducted under the supervision of J.G.S. and M.C. We express our appreciation to Joan Gay Snodgrass, Larry Jacoby, William Hirst, and Ron Kinchla, as well as Peter Graf, Daniel Schacter, and two unsigned reviewers for helpful comments on an earlier draft of this paper. We also thank Daniel Schacter and Lynn Cooper for providing copies of their possible and impossible object stimuli. Correspondence should be addressed to J. G. Seamon, Department of Psychology, Wesleyan University, Middletown, CT 06459-0408 (e-mail: jseamon@ wesleyan.edu). tention interval. Graf (1994); Moscovitch, GoshenGottstein, and Vriezen (1994); Richardson-Klavehn and Bjork (1988); Roediger and McDermott (1993); Schacter (1987); and Schacter, Chiu, and Ochsner (1993) provide comprehensive reviews of this research.

Research has also examined whether encoding and attentional manipulations, represented by variations in stimulus exposure time and attentional resources, can dissociate explicit and implicit memory. Stimulus exposure time and attentional resources at study can affect Norman and Bobrow's (1975) data-limited and resource-limited processes. Data-limited processes are influenced by characteristics of the stimuli presented to the subjects. They include characteristics such as stimulus exposure duration, size, and clarity that influence the accuracy of encoding (Norman \& Bobrow, 1975, p. 55). Resource-limited processes are influenced by the amount of attentional resources that subjects may invest in a task. According to Norman and Bobrow, performance on a cognitive task increases with the quality of the data available for encoding (data-limited processes) and the amount of resources invested in the task (resource-limited processes). Past research has shown that manipulating stimulus study time has dissociated explicit and implicit memory by affecting recognition but not priming (Jacoby \& Dallas, 1981; Musen, 1991; Seamon et al., 1995). However, the use of concurrent or divided attention tasks has consistently shown that recognition is impaired under conditions of limited attention, whereas implicit memory has been im- 
paired in some studies (e.g. Hawley \& Johnston, 1991) but not others (e.g., Jacoby, Woloshyn, \& Kelley, 1989; Parkin, Reid, \& Russo, 1990). These study time and attentional variables can be considered within the framework of data quality and attentional resource manipulations, respectively. Still other research has suggested that implicit memory is affected by attentional manipulations only in conceptually driven, not data-driven, tasks (e.g., Mulligan, 1997; Mulligan \& Hartman, 1996).

Prior studies of attention and memory have often used words as stimuli (e.g., Hawley \& Johnston, 1991; Jacoby et al., 1989, Weldon \& Jackson-Barrett, 1993). Because words are familiar stimuli, these studies have involved the activation of preexisting representations in memory, rather than the establishment of new representations. If the formation of new representations is more attention demanding than the activation of preexisting representations, then priming of unfamiliar stimuli should be more sensitive to a divided attention study condition than should priming of familiar stimuli. Smith and Oscar-Berman's (1990) finding of priming for words but not pseudowords under divided attention is consistent with this hypothesis. The present research provides a new empirical test of the relation between attention and explicit and implicit memory for unfamiliar visual stimuli. We used the recognition and object decision paradigm devised by Schacter and Cooper and their colleagues, because it has been extensively studied, and, more important, it has been useful in dissociating explicit and implicit memory (e.g., Schacter, Cooper, \& Delaney, 1990; Schacter, Cooper, Delaney, Peterson, \& Tharan, 1991).

To determine the extent to which divided attention affects implicit memory, we examined study time as an intervening variable. Specifically, we hypothesized that the shorter the study time, the more likely that limiting attentional resources by divided attention would impair implicit memory performance. This hypothesis was tested over two experiments in which study time was varied for full and divided attention conditions. Varying stimulus study time and limiting attentional resources by the use of a flanking digits task enabled us to examine their separate and combined effects on explicit and implicit memory.

\section{EXPERIMENT 1}

In a series of studies, Schacter and Cooper investigated subjects' memory for drawings of novel three-dimensional objects. Half of the drawings represented possible objects that could exist as three-dimensional forms, and half represented impossible objects that contained surface or edge violations that prevented them from existing as three-dimensional structures. Following the study phase, the subjects were given a surprise recognition or object decision test on studied and nonstudied figures. The recognition test, a measure of explicit memory, required the subjects to determine whether each object had been presented during study. The object decision test, a measure of implicit memory, asked them to classify each stimulus as a possible or an impossible object. Implicit memory was indicated when subjects showed priming in the form of greater object classification accuracy for studied than for nonstudied objects. Schacter et al. (1990; Schacter et al., 1991) found that while recognition was observed for possible and impossible objects, priming was found only for possible objects. Recognition and object decision priming have also been dissociated by other variables, including encoding instructions (Schacter et al., 1990; Schacter et al., 1991), stimulus transformations between study and test (Cooper, Schacter, Ballesteros, \& Moore, 1992), and study time (Schacter et al., 1991).

The purpose of Experiment 1 was to test the effect of limited attentional resources on recognition and object decision priming for possible and impossible objects. The full attention condition was a replication of the procedure previously used by Schacter et al. (1991, Experiment 2), in which the objects were presented five times for $1 \mathrm{sec}$ each at study. The divided attention condition involved a selection task in which the objects were flanked by single digits and subjects had to perform a perceptual classification of the digits at study. We used a flanking digits task to manipulate attention because it has been widely used in perception experiments, and it has been shown to interfere with encoding processes (see, e.g., Cohen \& Ivry, 1989; Treisman \& Schmidt, 1982). We suggest two hypotheses. First, if both explicit and implicit memory were influenced by resource-limited processes, divided attention at study should impair recognition and object decision priming relative to a full attention condition. Alternatively, if implicit memory were not influenced by resource-limited processes, divided attention at study should impair recognition but not object priming. In this case, priming should be demonstrated even when attention has been limited.

\section{Method}

Subjects. The subjects, 100 male and female Wesleyan University students who were 17-24 years old, received introductory psychology credit or served as paid volunteers. They were divided into four experimental groups and one control group of 20 subjects each. None had taken part in any previous implicit memory research.

Materials and Apparatus. The stimuli were line drawings of possible and impossible objects obtained directly from Schacter and Cooper (see Schacter et al., 1990, for examples). A total of 48 stimulus figures were used: Half were possible objects, and half were impossible objects. All of the stimuli were photographed as negative slides and presented on an $80 \times 106 \mathrm{~cm}$ screen by a Gerbrands projection tachistoscope. The object stimuli subtended a visual angle of approximately $5^{\circ}$ when viewed from a distance of $2.25 \mathrm{~m}$, and they appeared as green objects on a dark surround when shown through a green photographic filter attached to the lens shutter of the tachistoscope. All stimuli were viewed under conditions of low room illumination.

Procedure. At the beginning of the experiment, the subjects in the four experimental groups were told that they were taking part in a study of perception, and that they would see 120 stimuli presented sequentially on the screen. The stimuli consisted of 24 object figures, 12 possible and 12 impossible, shown five times in random or ders of 24. Each stimulus was presented for $1 \mathrm{sec}$, followed by a 4 sec interstimulus interval. The subjects, who were tested in groups 


\section{Study Conditions}

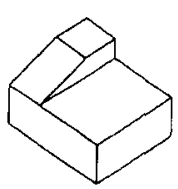

Possible Objects

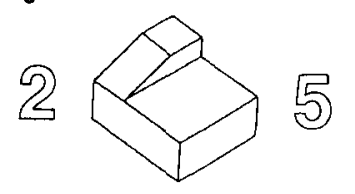

Impossible Objects
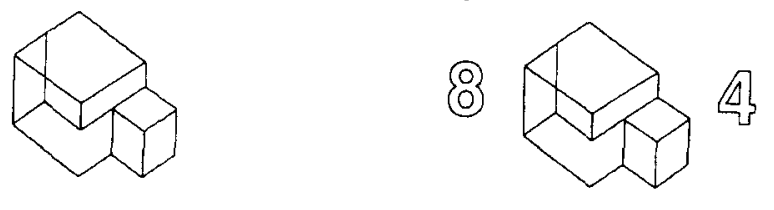

Full Attention

sheets. Examples of possible and impossible objects were shown and described before the test trials were presented. We note that all of the general procedures for the full attention study condition and test procedures for recognition and object decision priming were essentially the same as those used by Schacter et al. (1990; Schacter et al., 1991). The specific study conditions involving stimulus exposure duration and number of exposures were the same as those used by Schacter et al. (1991, Experiment 2).

Finally, a fifth group of 20 subjects served in an object decision control condition. These subjects received the object decision test without prior study trials to ensure that any demonstration of priming in the full or divided attention study conditions could not be due to the particular object stimuli assigned to the studied and nonstudied object sets.

\section{Results and Discussion}

The design for Experiment 1 was a mixed factorial in which attention at study (full vs. divided attention) and test type (recognition vs. object decision) were betweensubjects variables, whereas object type (possible vs. impossible objects) and item type (studied vs. nonstudied items) were within-subjects variables. Separate analyses were performed on the recognition and object decision data.

Recognition memory. Table 1 shows recognition performance in terms of hits and false alarms for studied and nonstudied objects in the full and divided attention conditions. From a signal detection viewpoint, a measure of hits minus false alarms confounds instructional effects and subjects' ability to discriminate studied and nonstudied stimuli (Kinchla, 1994; but see Snodgrass \& Corwin, 1988). However, to be consistent with previous research on recognition and object decision priming, hits minus false alarms will be the primary recognition measure, but $d^{\prime}$ will also be noted. Two findings are apparent. First, recognition memory for both object types was impaired by divided attention at study. Second, recognition did not vary greatly for possible and impossible objects. An analysis of variance on hits minus false alarms supported these observations. There was an overall effect of attention at study $\left[F(1,38)=69.13, M S_{\mathrm{e}}=4.19, p<\right.$ $.0001]$, as subjects recognized objects more accurately following full as opposed to divided attention, but there was no effect of object type $\left[F(1,38)=2.08, M S_{\mathrm{e}}=.04\right.$, $p>.10]$, and no interaction of attention and object type $\left[F(1,38)=1.50, M S_{\mathrm{e}}=.03, p>.10\right]$. Hits minus false alarms were greater than zero in all conditions, including possible $[t(19)=4.31]$ and impossible $[t(19)=2.91]$ objects under divided attention (all $p \mathrm{~s}<.01$ ). The same outcomes for all of these analyses were observed when the data were analyzed according to $d^{\prime}$. These results indicated that our attentional manipulation had an effect on explicit memory. Limiting attention by our flanking digits task impaired the recognition of possible and impossible objects.

Object decision priming. Table 2 shows mean classification accuracy for possible and impossible objects designated as studied and nonstudied for the 20 control subjects who received the object decision test without prior exposure to the study phase. An analysis of variance of these data revealed an effect of object type $[F(1,18)=$ 
Table 1

Mean Percent Object Recognition in Experiment 1

\begin{tabular}{|c|c|c|c|c|c|}
\hline \multirow[b]{3}{*}{ Object Type } & \multirow[b]{3}{*}{ Item Type } & \multicolumn{4}{|c|}{ Attentional Condition at Study } \\
\hline & & \multicolumn{2}{|c|}{ Full } & \multicolumn{2}{|c|}{ Divided } \\
\hline & & $M$ & $S E$ & $M$ & $S E$ \\
\hline \multirow[t]{3}{*}{ Possible } & Studied & 75.8 & 4.4 & 39.2 & 4.9 \\
\hline & Nonstudied & 12.5 & 2.5 & 25.4 & 3.2 \\
\hline & Hits - FAs & 63.3 & 5.4 & 13.8 & 3.2 \\
\hline \multirow[t]{3}{*}{ Impossible } & Studied & 70.4 & 4.2 & 41.7 & 5.7 \\
\hline & Nonstudied & 15.5 & 2.5 & 28.6 & 5.2 \\
\hline & Hits - FAs & 54.9 & 4.7 & 13.1 & 4.5 \\
\hline
\end{tabular}

Notes-The data reflect the percentage of studied (hits) and nonstudied (false alarms) objects called old.

11.64, $\left.M S_{\mathrm{e}}=.38, p<.005\right]$, but no effect of item type and no interaction of item and object type (both $F_{\mathrm{s}}<1$ ). The control subjects classified possible objects more accurately than impossible objects, but they showed no difference in classification accuracy for the possible or impossible objects designated as studied and nonstudied. ${ }^{1}$ These results indicated that priming in the full or divided attention conditions could not be attributed to the particular objects used as stimuli.

The object decision performance for subjects in the full and divided attention conditions is shown in Table 3. Two important observations can be made. First, object decision performance for possible objects was facilitated by a prior left-right encoding of those objects under conditions of both full and divided attention. This finding indicates priming for possible objects. Second, object decision performance for impossible objects was not facilitated by a prior encoding of those objects. In fact, in the full attention condition, impossible objects were classified better if they were nonstudied than if they were studied objects.

These observations were supported by the results of an analysis of variance. In the full attention condition, there was an effect of object type $\left[F(1,19)=14.36, M S_{\mathrm{e}}=.27\right.$, $p<.001]$, as subjects classified possible objects more accurately than impossible objects. There was also an interaction of object and item type $[F(1,19)=13.90$, $\left.M S_{\mathrm{e}}=.24, p<.001\right]$. Subjects classified studied objects more accurately than nonstudied objects if those objects were possible $\left[F(1,19)=7.73, M S_{\mathrm{e}}=.02, p<.01\right]$, but they demonstrated a trend in the opposite direction if the objects were impossible $\left[F(1,19)=3.66, M S_{\mathrm{e}}=.03, p<\right.$ $.08]$. These findings are similar to those of Schacter et al. (1990; Schacter et al., 1991), which showed priming for possible but not impossible objects, as well as a small, reversed effect for impossible objects in some conditions.

In the divided attention condition, there was an effect of object type $\left[F(1,19)=11.41, M S_{\mathrm{e}}=.18, p<.005\right]$, as possible objects were classified more accurately than impossible objects, and a marginal interaction of object and item type $\left[F(1,19)=3.14, M S_{\mathrm{e}}=.06, p<.1\right]$. Subjects classified possible objects more accurately if they were studied than if they were nonstudied $[F(1,19)=7.73$, $M S_{\mathrm{e}}=.02, p<.01 \mathrm{j}$, but there was no difference in clas- sification accuracy for studied and nonstudied impossible objects $(F<1)$.

The results of this experiment showed that priming of possible objects was insensitive to the manipulation of attentional resources at study. Even when the subjects directed their attention to the flanking digits at study, representations of the objects were created, as is indicated by the existence of priming for possible objects. Possible but not impossible objects were primed by a prior exposure, and the magnitude of this priming was essentially the same for possible objects perceived in the full $(11.6 \%)$ or divided $(10.6 \%)$ attention conditions. These results extend those of Schacter et al. (1990; Schacter et al., 1991) in demonstrating that it is not necessary to instruct subjects to encode the object figures globally in order to demonstrate priming in the object decision task. Priming was observed under conditions of divided attention without any specific instructions regarding the object figures. It may be that Schacter and Cooper's possible objects are normally encoded globally as three-dimensional objects. Studies that showed effects of encoding manipulations, such as those that instructed subjects to attend to local or global features (e.g., Schacter et al., 1990), may have impaired performance by local encoding, rather than enhanced it by global encoding. It is also worth noting that research has shown that global features are usually perceived before local features when the stimuli subtend visual angles that are less than $6^{\circ}$ (Kinchla \& Wolfe, 1979), a size magnitude that includes the stimuli of the present experiment.

The finding of a trend for greater classification accuracy for nonstudied than for studied impossible objects in the full attention condition suggests that a bias to give "possible" responses to studied objects may have been present. As noted by Schacter et al. (1991), a strong bias to classify all previously studied objects as possible would yield greater classification accuracy for studied possible objects and nonstudied impossible objects. Nominally greater classification accuracy for nonstudied than for studied impossible objects has been found in many of Schacter and Cooper's experiments (e.g., Cooper et al., 1992, Experiments 1-2; Schacter \& Cooper, 1993, Experiments 1 and 3-6; Schacter et al., 1990, Experiments 1-3; Schacter et al., 1991, Experiments 2-3), and Ratcliff and McKoon (1995) reported that classification accuracy averaged $2.2 \%$ higher for nonstudied than for studied impossible objects across all of Schacter and Cooper's studies. The accuracy difference for nonstudied and studied

Table 2

Mean Percent Object Classification Accuracy: Control Condition

\begin{tabular}{lccccccc}
\hline & \multicolumn{5}{c}{ Item Type } \\
\cline { 2 - 6 } Object Type & \multicolumn{2}{c}{ Studied } & & \multicolumn{2}{c}{ Nonstudied } & & \\
\cline { 2 - 5 } \cline { 5 - 7 } & $M$ & $S E$ & & $M$ & $S E$ & $M$ & $S E$ \\
\hline Possible & 76.3 & 3.5 & 76.4 & 3.1 & 76.3 & 2.3 \\
Impossible & 61.3 & 4.2 & 63.6 & 3.2 & 62.5 & 2.6 \\
$M$ & 68.8 & 3.0 & 70.0 & 2.4 & & \\
\hline
\end{tabular}


Table 3

Mean Percent Object Classification Accuracy in Experiment 1

\begin{tabular}{llccccc}
\hline & & \multicolumn{2}{c}{ Attentional Condition at Study } \\
\cline { 3 - 4 } Object Type & Item Type & \multicolumn{2}{c}{ Full } & & \multicolumn{2}{c}{ Divided } \\
\cline { 3 - 4 } \cline { 6 - 7 } & $M$ & $S E$ & & $M$ & $S E$ \\
\hline Possible & Studied & 79.7 & 4.0 & & 77.3 & 2.9 \\
& Nonstudied & 68.1 & 4.1 & & 66.7 & 3.4 \\
Impossible & Studied & 57.3 & 3.7 & 62.7 & 2.8 \\
& Nonstudied & 67.3 & 3.8 & 62.3 & 2.5 \\
\hline
\end{tabular}

impossible objects in the present full attention condition is somewhat larger than the mean difference from Schacter and Cooper's experiments. But even in their studies, accuracy differences for nonstudied and studied impossible objects occasionally reached $8 \%$ or $9 \%$, figures more comparable to the present result.

In summary, in this experiment we found that limiting attention at study impaired the recognition of both possible and impossible objects and eliminated a negative effect of study for impossible objects, but it had no effect on priming for possible objects. The demonstration of priming for previously novel possible objects following divided attention indicates that representations for unfamiliar visual stimuli can be created when limited resources and sufficient study time are available.

\section{EXPERIMENT 2}

In Experiment 2, we reduced stimulus study time and limited attentional resources to observe their combined effect on recognition and object decision performance. We hypothesized that study time would function as an intervening variable that determined the degree to which limited attentional resources impaired implicit memory performance. To test this hypothesis, we limited attentional resources at study by the use of the same flanking digits task as in our first experiment, and we shortened study time. Specifically, we reduced study time by presenting each $1-\sec$ stimulus three times instead of five times. Schacter et al. (1991, Experiment 2) found that reducing the study time from 5- to $1-\mathrm{sec}$ impaired recognition and eliminated object decision priming. Schacter et al. (1991) concluded that a single $1 \mathrm{sec}$ exposure did not provide sufficient time to compute representations for possible objects to produce priming in the object decision test. In Norman and Bobrow's (1975) terms, reducing stimulus study time may have limited the resultant quality of the data available for generating object representations. Therefore, we chose three 1 -sec exposures as a midway level between one and five exposures. For this number of exposures, the quality of the object representations that underlie recognition and priming may be more susceptible to the effect of divided attention.

\section{Method}

Subjects. The subjects, 80 male and female Wesleyan University students from the same subject pool used in Experiment 1, were divided into four groups of 20 subjects according to attentional con- dition (full or divided) and test type (recognition or object decision). None had participated in any previous implicit memory research.

Materials and Apparatus. The stimuli and test apparatus were the same as those used in Experiment 1.

Procedure. The stimuli consisted of 24 object figures, 12 possible and 12 impossible, shown three times in random orders of 24 for a total of 72 study trials. Aside from the reduction in the number of stimulus exposures from five to three, all other aspects of procedure and design were the same as in the first experiment

\section{Results and Discussion}

Recognition memory. Two findings can be seen in the recognition performance indicated by hits minus false alarms in Table 4. First, object recognition was impaired by divided attention at study. Second, recognition was better for possible than for impossible objects. An analysis of variance on hits minus false alarms showed overall effects of attention at study $\left[F(1,38)=59.70, M S_{\mathrm{e}}=3.32\right.$, $p<.0001]$, as objects were recognized more accurately following full as opposed to divided attention, and object type $\left[F(1,38)=12.75, M S_{\mathrm{e}}=.30, p>.001\right]$, as possible objects were recognized more accurately than impossible objects. There was no interaction of attention and object type $\left[F(1,38)=1.86, M S_{\mathrm{e}}=.04, p>.10\right]$. As in Experiment 1 , hits minus false alarms were greater than zero for possible and impossible objects in the full attention condition and for possible objects $[t(19)=4.17]$ in the divided attention condition (all $p \mathrm{~s}<.001$ ). Unlike in the first experiment, hits minus false alarms were only marginally greater than zero for impossible objects $[t(19)=1.69]$ in the divided attention condition $(p<.06)$. However, when the data were analyzed according to $d^{\prime}$, recognition memory was greater than zero in all conditions (all $p s<.05$ ). Otherwise, all statistical outcomes were the same for hits minus false alarms and $d^{\prime}$.

To determine the effect of study time on recognition performance, we treated this manipulation as a betweensubjects variable across Experiments 1 and 2 . The design for this analysis was a mixed factorial in which attention at study (full vs. divided attention) and study time (5 vs. $3 \mathrm{sec}$ ) were between-subjects variables, whereas object type (possible vs. impossible objects) was a withinsubjects variable. Because the results pertaining to variables other than study time have already been reported, we will report only the findings involving study time. The hits minus false alarms results indicated that reducing

Table 4

Mean Percent Object Recognition in Experiment 2

\begin{tabular}{|c|c|c|c|c|c|}
\hline \multirow[b]{3}{*}{ Object Type } & \multirow[b]{3}{*}{ Item Type } & \multicolumn{4}{|c|}{ Attentional Condition at Study } \\
\hline & & \multicolumn{2}{|c|}{ Full } & \multicolumn{2}{|c|}{ Divided } \\
\hline & & $M$ & $S E$ & $M$ & $S E$ \\
\hline \multirow[t]{3}{*}{ Possible } & Studied & 75.8 & 3.1 & 39.6 & 3.7 \\
\hline & Nonstudied & 16.2 & 2.1 & 25.4 & 3.4 \\
\hline & Hits - FAs & 59.6 & 4.5 & 14.2 & 3.4 \\
\hline \multirow[t]{3}{*}{ Impossible } & Studied & 65.0 & 4.6 & 47.0 & 3.5 \\
\hline & Nonstudied & 22.3 & 3.1 & 40.4 & 4.3 \\
\hline & Hits - FAs & 42.7 & 4.7 & 6.6 & 3.9 \\
\hline
\end{tabular}

Notes-The data reflect the percentage of studied (hits) and nonstudied (false alarms) objects called old. 
Table 5

Mean Percent Object Classification Accuracy in Experiment 2 Attentional Condition at Study

\begin{tabular}{|c|c|c|c|c|c|}
\hline \multirow[b]{3}{*}{ Object Type } & \multirow[b]{3}{*}{ Item Type } & \multicolumn{4}{|c|}{ Altenitiontal Conumition al study } \\
\hline & & \multicolumn{2}{|c|}{ Full } & \multicolumn{2}{|c|}{ Divided } \\
\hline & & $M$ & $S E$ & $M$ & $S E$ \\
\hline \multirow[t]{2}{*}{ Possible } & Studied & 81.7 & 2.5 & 73.3 & 2.3 \\
\hline & Nonstudied & 66.8 & 4.3 & 72.1 & 2.7 \\
\hline \multirow[t]{2}{*}{ Impossible } & Studied & 58.4 & 3.0 & 65.9 & 2.9 \\
\hline & Nonstudied & 66.6 & 2.5 & 65.1 & 2.7 \\
\hline
\end{tabular}

study time from 5 to $3 \mathrm{sec}$ lowered recognition performance for impossible objects [ $34.0 \%$ vs. $24.7 \% ; F(1,76)=$ $\left.3.9, M S_{\mathrm{e}}=0.17, p<.05\right]$, but not possible objects $(38.5 \%$ vs. $36.9 \% ; F<1$ ). No other effects involving this variable were significant (all $p s>.10$ ).

Unlike the results of Schacter et al. (1991), who reported that decreasing study time from 5 to $1 \mathrm{sec}$ affected recognition for both object types, the present results showed that a more limited reduction in exposure duration from 5 to $3 \mathrm{sec}$ produced an effect only for impossible objects in both attentional conditions. We did not use a 1 -sec exposure to the stimuli, because it yielded no object priming in their research. The present finding of an effect of study time on recognition for impossible but not possible objects may be viewed within the context of differences in perceived complexity for Schacter and Cooper's possible and impossible objects (see Carrasco \& Seamon, 1996). ${ }^{2}$ In the present study, we found that a reduction in the total study time from 5 to $3 \mathrm{sec}$ affected only the recognition of the more complex (impossible) objects, whereas Schacter et al. (1991) found that a reduction in study time from 5 to $1 \mathrm{sec}$ affected the recognition of both object types.

Object decision priming. Two primary observations can be made about the object decision performance shown in Table 5. First, under conditions of full attention, studying the objects with the left-right encoding rule had opposite effects on the two object types. Previously studied possible objects were classified more accurately than nonstudied possible objects, whereas the opposite was true for impossible objects. Second, under conditions of divided attention, prior exposure had no effect on either object type. An analysis of variance supported these observations. In the full attention condition, there was an effect of object type $\left[F(1,19)=14.66, M S_{\mathrm{e}}=.28, p<.005\right]$, as possible objects were classified more accurately than impossible objects. There was also an interaction of object and item type $\left[F(1,19)=20.62, M S_{\mathrm{e}}=.27, p<.001\right]$. For possible objects, studied objects were classified more accurately than nonstudied objects $[F(1,19)=16.53$, $\left.M S_{\mathrm{e}}=.01, p<.005\right]$; for impossible objects, nonstudied objects were classified more accurately than studied objects $\left[F(1,19)=5.25, M S_{\mathrm{e}}=.01, p<.05\right]$. The same general pattern of results was observed in the first experiment. These findings also extend those of Schacter et al. (1991), who concluded that $1-5 \mathrm{sec}$ are necessary in order to generate representations of possible objects to facilitate their subsequent processing. The present findings indicate that $3 \mathrm{sec}$ are sufficient to demonstrate priming in the object decision task under conditions of full attention.

In the divided attention condition, there was an effect of object type $\left[F(1,19)=5.63, M S_{\mathrm{e}}=.10, p<.05\right]$, as possible objects were classified more accurately than impossible objects. However, there was no effect of item type and no interaction of object and item type (both $F_{\mathrm{S}}<1$ ). Whereas three exposures to the object figures under full attention were sufficient to demonstrate priming for possible objects, three exposures to these stimuli under divided attention showed no effect of prior exposure on the object decision task. Because we previously observed priming following divided attention, we attribute the lack of priming in this experimental condition to the interactive effect of reduced study time and limited attentional resources. In addition, our finding that recognition for impossible objects was influenced by study time across experiments provided an independent indication that our divided attention condition was more effective in Experiment 2 than in Experiment 1.

Finally, we note that there is no evidence to suggest that the priming of possible objects in the divided attention condition of Experiment $l$ was due to the subjects' being more practiced at the flanking digits task in Experiment 1 (five trials per stimulus) than in Experiment 2 (three trials per stimulus). If the subjects in these conditions had been influenced by practice on the flanking digits, in such a way that the subjects in the first experiment were better able to divide their attention between the digits and the object stimuli than the subjects in the second study, the subjects in Experiment 1 should have demonstrated better object recognition than did the subjects in Experiment 2. However, Tables 1 and 4 show no difference in the recognition of possible objects (the same objects that showed priming) for subjects in the divided attention conditions.

\section{GENERAL DISCUSSION}

In Experiment 1, we found that limiting attentional resources during study impaired the subsequent recognition of possible and impossible objects, eliminated a negative effect of study for impossible objects, and had no effect on priming for possible objects. The finding of implicit memory for previously unfamiliar possible objects following divided attention suggests that object representations can be formed when attentional resources are limited. In Experiment 2, we showed that when attentional resources were limited and study time was reduced, recognition of both object types was poor, there was no effect of study for impossible figures, and there was no priming for possible objects. Together, these results indicate that study time functioned as an intervening variable that mediated the effect of attention on implicit memory. Implicit memory was affected more by divided attention when study time was reduced. These findings demonstrate that attention can have qualitatively similar but quantitatively different effects on explicit and implicit memory. Implicit memory, as indicated by perceptual priming of previously unfamiliar objects, is less sensitive than ex- 

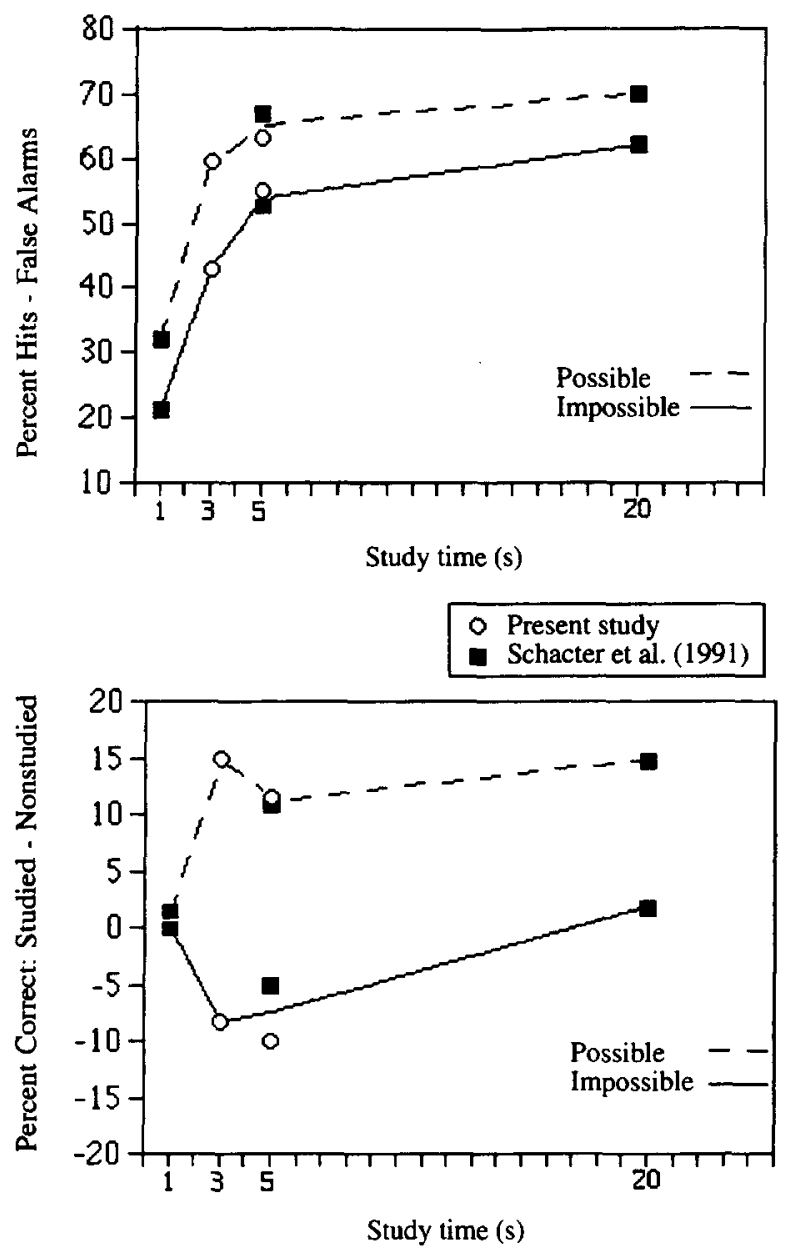

Figure 2. Top panel: mean recognition performance, expressed as the percentage of hits minus false alarms. Bottom panel: mean object decision priming, expressed as the percentage of correct object classifications for studied objects minus nonstudied objects. Both recognition and priming are expressed as a function of stimulus study time for the present Experiments 1 and 2 and Schacter et al.'s (1991) Experiments 1 and 2.

plicit memory to limited attentional resources, but neither expression of memory is attention free.

\section{The Effects of Study Time and Attentional Resources}

Research has shown that increasing study time beyond a minimal threshold improves recognition but has little effect on priming (e.g., Jacoby \& Dallas, 1981; Schacter et al., 1991; Seamon, Marsh, \& Brody, 1984). The present results are consistent with those findings and extend the results of Schacter et al. (1991). The top panel of Figure 2 presents our full attention recognition results together with those of Schacter et al. (1991). This comparison is justified because the same set of object stimuli was used in both studies, the present procedure was the same as that used by Schacter et al. (1991, Experiment 2), and the same conditions produced highly similar results. As the figure indicates, the pooled data across experiments provided continuous recognition functions for possible and impossible objects. Possible objects were recognized better than impossible objects for all stimulus exposure durations, and recognition improved logarithmically as exposure duration increased from 1 to $20 \mathrm{sec}$.

A comparison of object decision performance across the same experimental conditions is presented in the bottom panel of Figure 2. Whereas recognition improved with longer exposure durations, priming of possible objects suggested an "all or none" relation to exposure duration. It was absent for a 1 -sec stimulus exposure, and fully present when that duration was increased to $3 \mathrm{sec}$. Extending study exposures from 3 to $20 \mathrm{sec}$ had no effect on the magnitude of possible object priming. Interestingly, a negative effect of prior study was observed for impossible objects, but only for 3- to 5-sec exposure durations. Together, the results shown in Figure 2 indicate that combining the results of the present experiments with those of Schacter et al. (1991) yielded consistent findings regarding the effects of study time on recognition and priming performance.

The present results also indicate that study time can mediate the effect of attentional resources on priming. This finding is consistent with the results of other studies in which sufficient study time has been necessary to demonstrate implicit memory for unfamiliar visual stimuli; when study time was sufficiently shortened, implicit memory effects disappeared (e.g., Schacter et al., 1991; Seamon, Brody, \& Kauff, 1983). In the present context, implicit memory following divided attention at study occurred only if study time was sufficient to allow representations for previously unfamiliar stimuli to be generated. We suggest that the shorter the study time, the poorer the data quality, and the more critical that attentional resources will be for demonstrating implicit memory.

\section{Attentional Requirements for Recognition and Perceptual Priming}

The present results showed that recognition was more sensitive than object decision priming to limited attentional resources at study. The reason for this difference may lie in the different requirements made by the two memory tests. Successful performance on a perceptual priming test depends on activating representations for familiar stimuli or generating representations for novel stimuli in memory. Further elaboration of those representations has not been found to be beneficial (Graf \& Mandler, 1984; Jacoby \& Dallas, 1981; Schacter et al., 1990). On the other hand, successful performance on a recognition memory test requires not only the activation or generation of stimulus representations, but also that the stimuli be encoded in memory in terms of contextual cues regarding their time and place of occurrence. Encoding of information that will be helpful in an explicit memory test may thus place a heavier demand on attentional resources than does encoding of information that will be useful in an implicit memory test. 


\section{Bias in the Object Decision Task}

In the full attention conditions of Experiments 1 and 2, we found priming for possible objects but a negative effect of study for impossible objects. We noted that our results for impossible objects suggested the existence of a bias, because subjects showed a tendency to classify studied impossible objects as possible. Ratcliff and McKoon (1995) have proposed that this effect is based on two opposing processes. First, subjects have a bias, based on a sense of stimulus familiarity, to classify all previously studied objects as possible. Second, subjects use stimulus information from explicit memory about some feature or combination of features of a previously studied object that indicates whether the object is possible or impossible. According to Ratcliff and McKoon, experimental conditions that produce poor explicit memory result in more accurate object decisions for nonstudied than for studied impossible objects because decisions involving studied objects are influenced by the bias. However, in both of the present experiments, we found that although divided attention at study greatly reduced explicit memory for possible and impossible objects, it reduced rather than enhanced the tendency of subjects to misclassify studied impossible objects as possible. This result is inconsistent with expectations based on Ratcliff and McKoon's twoprocess model of object decision priming for possible and impossible objects. Similarly, Schacter and Cooper (1995) reported that they found no evidence of an increased bias in amnesic subjects who showed normal object priming, despite impaired object recognition (but see McKoon \& Ratcliff, 1995, for criticism of this research). Schacter and Cooper (1995) suggested that a bias effect might reflect explicit, not implicit, memory processes.

A direct comparison between the present findings and the results reported by Ratcliff and McKoon (1995) cannot be made, because we manipulated attention at study, whereas they manipulated attention at test. In addition, our use of a recognition test provided an independent indication that divided attention reduced explicit memory; Ratcliff and McKoon provided no corresponding measure. Note that without a recognition test, they had no method of verifying whether their attempts to manipulate the explicit component of retrieval directly impaired explicit performance in their test conditions.

\section{Process Pure Memory Tests}

According to Jacoby (1991), dissociations between explicit and implicit tests can lead to problems of interpretation if researchers treat their results as though performance on each memory measure were process pure- that is, based on a single process that is different for each test. In the present context, Jacoby's research has serious implications for any study of the effects of attentional manipulations on explicit and implicit memory. If implicit memory performance is contaminated by explicit memory, a divided attention task may impair implicit performance by reducing or eliminating the explicit component, the implicit component, or both. Alternatively, if that performance is based solely on implicit memory, a divided attention task may impair performance only by reducing or eliminating implicit memory. Without denying the importance of Jacoby's concerns, we argue that priming for possible objects in the present experiments was not contaminated by explicit memory.

The opportunity for explicit contamination of our object decision test, though present in both experiments, was greater in the first than in the second because there were more stimulus exposures during study in Experiment 1 than in Experiment 2. If so, we might expect that divided attention at study would have impaired priming in Experiment 1 if that priming had been based on explicit memory. However, we found that divided attention had no measurable effect on priming for possible objects in Experiment 1 , whereas divided attention and fewer exposures eliminated priming for these objects in Experiment 2. These results are inconsistent with an interpretation of priming for possible objects based on explicit memory. In addition, divided attention impaired recognition memory in both experiments. Consequently, if the same form of explicit memory guided performance in the recognition and object decision tests, priming for possible objects should have been impaired in both experiments. The fact that only Experiment 2 showed an effect of attention on possible object priming is at odds with an explicit contamination interpretation. We conclude that priming for possible objects was not due to contamination by explicit memory.

In summary, the transitory nature of the attentional dissociation observed in the present experiments showed that the presence or absence of a dissociation was dependent on the intervening variable of study time. Recognition memory and perceptual priming for previously unfamiliar visual stimuli were both influenced by attention, although to different degrees. This finding is important, because some researchers have concluded that attentional resources (beyond those needed for identification), though important for conceptual priming, are not important for perceptual priming (e.g., Mulligan, 1997; Mulligan \& Hartman, 1996). Our results lead us to disagree: Perceptual implicit memory, as measured by the object decision task, is dependent on both attentional resources and study time.

\section{REFERENCES}

Carrasco, M., \& Seamon, J. G. (1996). Priming impossible figures in the object decision task: The critical importance of perceived stimulus complexity. Psychonomic Bulletin \& Review, 3, 344-351.

COHEN, A., \& IVRY, R. (1989). Illusory conjunctions inside and outside the focus of attention. Journal of Experimental Psychology: Human Perception \& Performance, 15, 650-663.

Cooper, L. A., Schacter, D. L., Ballesteros, S., \& Moore, C. (1992). Priming and recognition of transformed three-dimensional objects: Effects of size and reflection. Journal of Experimental Ps. chology: Learning, Memory, \& Cognition, 18, 43-57.

GRAF, P. (1994). Explicit and implicit memory: A decade of research. In C. Umiltà \& M. Moscovitch (Eds.), Attention and performance $X V$. Conscious and nonconscious information processing (pp. 681-696). Cambridge, MA: MIT Press.

Graf, P., \& Mandler, G. (1984). Activation makes words more accessible, but not necessarily more retrievable. Joumal of Verbal Learning \& Verbal Behavior, 23, 553-568. 
GRAF, P., \& Schacter, D. L. (1985). Implicit and explicit memory for new associations in normal and amnesic subjects. Journal of Experimental Psychology: Learning, Memory, \& Cognition, 11, 501-508.

HAWLEY, K. J., \& JoHNSTON, W. A. (1991). Long-term perceptual memory for briefly exposed words as a function of awareness and attention. Journal of Experimental Psychology: Human Perception \& Performance, 17, 807-815.

JACOBY, L. L. (1991). A process dissociation framework: Separating automatic from intentional uses of memory. Journal of Memory \& Language, 30, 513-541.

JACOBY, L. L., \& DaLlas, M. (1981). On the relationship between autobiographical memory and perceptual learning. Journal of Experimental Psychology: General, 110, 306-340.

JaCOBY, L. L., WoloshyN, V., \& Kelley, C. (1989). Becoming famous without being recognized: Unconscious influences of memory produced by dividing attention. Journal of Experimental Psychology. General, 118, 115-125.

KinCHLA, R. A. (1994). Comments on Batchelder and Reiffer's multinomial model of source monitoring. Psychological Review, 101, 166-171

KinCHLA, R. A., \& WolfE, J. M. (1979). The order of visual processing: "Top-down," "bottom-up," or "middle-out." Perception \& Psychophysics, 25, 225-231.

MCKoon, G., \& RATCLIFF, R. (1995). How should implicit memory be modeled? Journal of Experimental Psychology: Learning, Memory, \& Cognition, 21, 777-784

Moscovitch, M., Goshen-Gottstein, Y., \& Vriezen, E. (1994). Memory without conscious recollection: A tutorial review from a neuropsychological perspective. In C. Umiltà \& M. Moscovitch (Eds.), Attention and performance $X V$ : Conscious and nonconscious information processing (pp. 619-660). Cambridge, MA: MIT Press.

Mulligan, N. W. (1997). Attention and implicit memory tests: The effects of varying attentional load on conceptual priming. Memory \& Cognition, 25, 11-17.

Mulligan, N. W., \& Hartman, M. (1996). Divided attention and indirect memory tests. Memory \& Cognition, 24, 453-465.

Musen, G. (1991). Effects of verbal labeling and exposure duration on implicit memory for visual patterns. Journal of Experimental Psychology: Learning, Memory, \& Cognition, 17, 954-962.

Norman, D. A., \& Bobrow, D. G. (1975). On data-limited and resource-limited processes. Cognitive Psychology, 7, 44-64.

Parkin, A. J., ReID, T. K., \& Russo, R. (1990). On the differential nature of implicit and explicit memory. Memory \& Cognition, 18, 507-514

Ratcliff, R., \& MCKoon, G. (1995). Bias in the priming of object decisions. Journal of Experimental Psychology: Learning, Memory, \& Cognition, 21, 754-767.

Richardson-KLAVEHN, A., \& BJork, R. A. (1988). Measures of memory. Annual Review of Psychology, 39, 475-543.

RoEDiger, H. L., III, \& MCDERMOTT, K. B. (1993). Implicit memory in normal subjects. In F. Boller \& J. Grafman (Eds.), Handbook of neuropsychology (pp. 63-131). Amsterdam: Elsevier.

SCHACTER, D. L. (1987). Implicit memory: History and current status Journal of Experimental Psychology: Learning, Memory, \& Cognition, 13, 501-518.

Schacter, D. L., Chiu, P. C. Y., \& OchSner, K. N. (1993). Implicit memory: A selective review. Annual Review of Neuroscience, 16, 159-182.

SCHACTER, D. L., \& COOPER, L. A. (1993). Implicit and explicit memory for novel visual objects: Structure and function. Journal of Experimental Psychology: Learning, Memory, \& Cognition, 19, 995-1009.
Schacter, D. L., \& CoOper, L. A. (1995). Bias in the priming of object decisions: Logic, assumption, and data. Journal of Experimental Psychology: Learning, Memory, \& Cognition, 21, 768-776.

SChacter, D. L., CoOper, L. A., \& Delaney, S. M. (1990). Implicit memory for unfamiliar objects depends on access to structural description. Journal of Experimental Psychology: General, 119, 5-24.

Schacter, D. L., Cooper, L. A., Delaney, S. M., Peterson, M. A., \& Tharan, M. (1991). Implicit memory for possible and impossible objects: Constraints on the construction of structural description. Journal of Experimental Psychology: Learning, Memory, \& Cognition, 17, 3-19.

Seamon, J. G., Brody, N., \& KaufF, D. M. (1983). Affective discrimination of stimuli that are not recognized: Effects of shadowing, masking, and cerebral laterality. Journal of Experimental Psychology: Learning, Memory, \& Cognition, 9, 544-555.

Seamon, J. G., Marsh, R. L., \& Brody, N. (1984). Critical importance of exposure duration for affective discrimination of stimuli that are not recognized. Journal of Experimental Psychology: Learning, Memory, \& Cognition, 10, 465-469.

Seamon, J. G., Williams, P. C., Crowley, M. J., Kim, I. J., Langer, S. A., ORNE, P. J., \& WISHENGRAD, D. L. (1995). The mere exposure effect is based on implicit memory: Effects of stimulus type, encoding conditions, and number of exposures on recognition and affect judgments. Journal of Experimental Psychology: Learning, Memory, \& Cognition, 21, 711-721.

SMith, M. E., \& Oscar-Berman, M. (1990). Repetition priming of words and pseudowords in divided attention and in amnesia. Journal of Experimental Psychology: Learning, Memory, \& Cognition, 16, 1033-1042.

SNodgrass, J. G., \& Corwin, J. (1988). Pragmatics of measuring recognition memory: Applications to dementia and amnesia. Journal of Experimental Psychology: General, 117, 34-50.

Treisman, A., \& SchmidT, H. (1982). Illusory conjunctions in the perception of objects. Cognitive Psychology, 14, 107-141

WELDON, M. S., \& JaCKSON-BARRETT, J. L. (1993). Why do pictures produce priming on the word-fragment completion test? A study of encoding and retrieval factors. Memory \& Cognition, 21, 519-528.

\section{NOTES}

1. Although our control subjects classified possible objects more accurately than impossible objects, regardless of their studied or nonstudied designation, our experimental subjects classified the nonstudied possible and impossible objects at equivalent rates. Collapsing the data over both experiments and attention conditions, mean classification accuracy for the experimental subjects was $67.1 \%$ for nonstudied possible objects and $66.7 \%$ for nonstudied impossible objects (data from means in Tables 3 and 5). These means correspond closely to those reported by Schacter et al. (1990; Schacter et al., 1991) for nonstudied objects. We attribute the high performance of our control subjects on the possible objects to a simple difference between groups in our experiment. The more important point is that the control subjects showed no difference in classification accuracy for either possible or impossible objects designated as studied or nonstudied.

2 . The research on perceived complexity for possible and impossible objects was done subsequent to the present studies. Therefore, the present stimuli were not selected on the basis of perceived complexity.

(Manuscript received February 4, 1997; revision accepted for publication June 26,1997 .) 